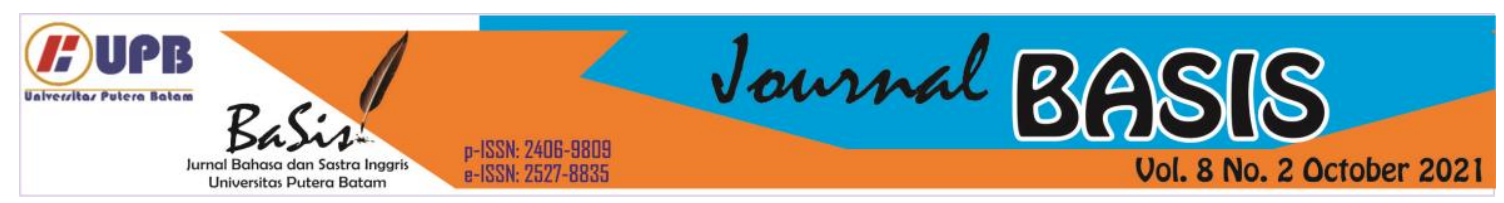

\title{
BROCA APHASIA LANGUAGE IMPAIRMENT IN SARAH SCOTT'S YOUTUBE CHANNEL
}

\author{
Arswenda Dini Mulia ${ }^{1}$ \\ Universitas Islam Negeri Maulana Malik Ibrahim Malang, Indonesia \\ senda04a1@gmail.com \\ Rohmani Nur Indah ${ }^{2}$ \\ Universitas Islam Negeri Maulana Malik Ibrahim Malang, Indonesia \\ indah@bsi.uin-malang.ac.id
}

\begin{abstract}
Aphasia is a language disorder caused by brain damage and makes the patient lose or impair language skills. One of the diseases which often cause people to experience aphasia is stroke. In this study, the researchers observed the characteristics of language impairment of Sarah Scott. She's a young woman suffering from Broca's aphasia after stroke. This study employed a qualitative descriptive method on the utterances she produced in SymphUK YouTube channel as the data source. In collecting the data, the researchers watched and transcribed the utterances containing the language disorder. The analysis used the theory of Hallowel (2017) on the characteristics of Broca's aphasia and Ardila (2014) about the linguistics defects in aphasia. The finding shows that the most dominant characteristic was dysnomia, literal (phonemic) paraphasia, and agrammatism among twenty-six utterances. Then, the other characteristics that also appeared were disfluency, repetition, and telegraphic speech. Furthermore, the levels of language-impaired in Sarah Scott were morphemic, morphosyntactic, and phonetic. Thus, the following study should cover more subjects with different age, gender, and language to see whether more variation of characteristics of Broca's aphasia appears in different contexts.
\end{abstract}

Keywords: Aphasia, Broca Aphasic, Language Impairment

\section{INTRODUCTION}

Speech disorder belongs to a linguistic phenomenon that can appear in any language. It is due to the fact that anyone can experience a language disorder. However, people who suffer from speech disorders will experience difficulties, especially in producing or understanding a language. Medically this language disorder is called aphasia, a brain damage causing the patient loss or impairment of language skills.
Consequently, it has linguistic and neurological dimension (Ardila, 2014).

The neurological dimension of language disorder occurs in the case of aphasia. Aphasia is known from the damage of the left hemisphere, which are classified into classic types, namely fluent or non-fluent (Code, 2019), anterior or posterior, and expressive or receptive aphasias (Hallowell, 2017) or in other terms Wernicke or Broca 
Aphasia. Wernicke aphasics are characterized by a limited understanding of what other people say, a high level of paraphasias, and classified as fluent speech (Jordan \& Keiser, 1996).

Another type of aphasia causing sufferers to have problems in producing the language is Broca aphasia, which is often referred to as expressive or nonfluent aphasia. People with Broca's aphasia can understand speech or conversation but have a problem in speaking, writing, and reading (Indah \& Abdurrahman, 2008). Furthermore, the loss of ability makes Broca's aphasia sufferers have difficulty communicating, characterized as speech output exhibiting poorly articulated words missing, added or transposed sounds, initiating speech, and reduced vocabulary (Withaker, 2007,). On the other hand, another problem experienced by people with aphasia syndrome is damage to linguistics aspects, including phonetics, morphemic, morphosyntactic, semantic, and pragmatic (Ardila, 2014).

Those difficulties can be seen in the young aphasic, Sarah Scott. Unlike stroke sufferers in general, which adults predominantly suffer, she was convicted of suffering from expressive Aphasia or Broca's aphasia at 18th years old (Project, 2021). It causes her language abilities lost. Sarah Scott recounts her condition and updates her speech therapist on her own YouTube channel, namely SymphUK. However, in telling her story, Sarah Scott seems too hard to convey her idea. She tells stories with short sentences, uses gestures, and remembers numbers, which is her significant problem.
Several researchers did some previous studies on aphasia. For example, Septianto (2020) found that people with Broca's aphasia have several characteristics: agrammatism, non-fluent, repetition, naming, phonetic deviation, phonological literal paraphasia, and verbal paraphasia. On the other hand, in Syarifah (2020) mentioned some difficulties of Broca's aphasic that affect the linguistics elements: lexical error, morphological error, and phonological error. Furthermore, Yulia et al. (2018) showed that the syntactic structure also becomes a significant problem for people with Broca's aphasia, namely telegraphic speech, a short sentence, two words, and holophrastic.

Unlike the previous studies, this study analyzes Broca's aphasia's characteristics and the levels of linguistics impairment on the patient. The object investigated in this study is an individual with Broca's aphasia named Sarah Scott in the ShympUK YouTube channel. The researcher used this YouTube channel for this study: first, this YouTube channel has many viewers. This channel is purposely created to show how people with language disorder can recover after brain damage. Second, this channel consists of several videos, so that the researchers can find many characteristics of Broca's aphasia and the levels of language impairments phenomenon on the patient. To analyze the data, the researchers used the theory proposed by Hallowell (2017) on the characteristic of aphasia and Ardila (2014) on the linguistics defects in aphasia. 


\section{LITERATURE REVIEW}

A language disorder arises from impairments at different processing structures: input, output, and word meaning. Most linguists and clinicians differentiated language disorder by the deficit of two components, namely expressive and receptive. The deficiency of expressive refers to the output processes, producing semantically with the correct grammatical sentences and following pragmatics rules of conversation. Meanwhile, deficits in receptive language affect comprehension, including input processes (Reily, 2014).

Language disorder can be defined as a communication disorder in which the sufferer has difficulty interacting with others, inability to express the idea, the use of words and their meaning is not proper, inability to use the correct grammatical, the vocabularies are reduced, and they cannot follow the directions (Nichcy, 2011). Several causes of language disorder are categorized into developed language disorder: inability to speak fluently, which acquired since newborn, and acquired language disorder caused by stroke, brain injury, and aging (Indah, 2011). It could also happen because of traumatic experience (Rahmi \& Arianto, 2019).

Aphasia refers to the impairment of language caused by brain damage on the left hemisphere, which is the core part of language components such as semantics (word and sentence meaning), syntax (grammatical structure), morphology (word structure), and phonology (sound structure) (Code, 2019). In Broca's aphasia, the patients know what they want to say, but their ability to generate the correct sentences with grammatical rules can be a significant problem. Furthermore, small word like conjunctions (and, or, but), article ( $\mathrm{a}$, an, the) can be eliminated which lead to the telegraph quality of their speeches (Indah \& Abdurrahman, 2008). Compared to Wernicke aphasia, Azad (2020) concluded that the person with Broca's aphasia committed less errors and responded more quickly. The utterance of patients with Broca's aphasia also show significant frequency differences exists between words produced correctly and those produced erroneously (Heal, 2019).

Broca's aphasia patients are various in age. For young adult aphasic, particularly of stroke survivors with aphasia, the communication impairment results in significant changes in their social network structure. In addition, the observed social change is affected by the level of communication impairment or the speech disorder they suffered (Ellis et al., 2019). In this case, they need the involvement of speech therapist to eliminate the communication impairment so that they can get a better social involvement. The support of communication partners to help them cope with their aphasia becomes a meaningful key for better social participation (Souchon et al., 2020).

\section{RESEARCH METHOD}

This study uses a descriptive qualitative method because the data are in the form of sentences produced by Sarah Scott, a young sufferer of Broca's aphasia. Qualitative research is concerned with developing social 
phenomena (Beverley, 1998; Hancock, 1998). The purpose of the study is to understand the reality of phenomena in depth and detail. As Bodgan and Biklen (1982) stated, qualitative research is descriptive in which the number did not collect the data, but the data are in the form of words or pictures. By employing this method, the present study tries to describe and interpret the utterances of Broca's aphasic which approve of reality.

\subsection{Data Collection}

In collecting the data, several processes were taken by the researchers. The first process is the researchers watched the videos related to the characteristics of the Broca's aphasia language impairments in the SymphUK YouTube channel. Then the next process was doing the transcription of the conversation. Furthermore, the second step is the researchers investigated the part of the videos appropriate for the study. The last step is the researchers collected the utterances containing the speech disorder as the data. As the final stage is data reduction to ensure that all the data represented the speech disorder found in the YouTube channel.

\subsection{Data Analysis}

After collecting the data, the analysis is conducted of each section based on the difficulties experienced by Sarah Scott when she was producing words, especially when she told her story and tried to convey her idea in the appropriate sentences. Finally, the data were classified based on how Sarah Scott produced the language. The data classification aimed to make it easier to understand Broca's aphasia's characteristic, experienced by Sarah Scott.

The function of the data is to increase the knowledge about the language, mind, and language disorders experienced by people with aphasia. To discuss and develop the research, the researchers used the theory of Hallowell (2017) on the characteristics of aphasia. The discussion of the study covered two major aspects, namely the Broca aphasia's characteristics and the types of language impairments experienced by Sarah Scott in the SymphUK YouTube channel.

\section{RESULT AND DISCUSSION}

The researcher found several problems of Sarah Scott when she produced the sentence and conversed with her mother, which led to Broca's aphasia's characteristics. Individuals with Broca's aphasia tend to non-fluent and poorly articulated, but the understanding of the language is relatively standard. In this study, Sarah Scott's utterances which shows several characteristics of Broca's aphasia cover twenty-six speech errors Those characteristics are agrammatism, telegraphic speech, dysnomia, literal (phonemic) paraphasia, disfluent, and repetition.

\section{a. Dysnomia}

Dysnomia was the characteristic of Broca's aphasia which tend to produce by Sarah Scott in the SymphUK YouTube channel. Dysnomia occurred when the person with Broca's aphasia had difficulty defining something. They tend to use circumlocutions or other words to get the closest word and 
related meaning that they are difficult to say (Hallowell, 2017). Moreover, according to Ardila (2014), dysnomia can be defined as the difficulty of wordfinding and classified into several types, such as doing confrontation, which means line drawing and photographs the function word (noun and verb) difficulty to define some objects and fluency.

Dysmonia occurs in datum 4 with the context when Sarah wanted to say that she had suffered from aphasia, however she had difficulty to say that word and writing down the word "aphasia" to make it easier. She said, "Err.. yep.. (writing down) apha.. aphasia.". Sarah Scott claimed that writing down the word that she wants to say can help her communicate with others. It occurred because Broca aphasic person has problems with wordfinding, so she has to write it first to make it easier to find the words that she wants to say.

Another example of dysmonia is in datum 5; in this case, Sarah had difficulty finding the word "therapy". So, she said, "Oh.. um. speech lang (language) um.. the.. speech.. umm". She produced this sentence when Joannie Scott asked her about her activities after a stroke hit her. After that, Sarah Scott tried to explain her activities as a person who suffered a stroke. The activity is speech therapy. However, Sarah cannot find the word therapy. It caused many pauses in Sarah's utterance, and Joannie Scott helps her answer it. There are many pauses and humming as signs that she had challenges producing the word from her utterance.
The dysnomia characteristics happened when Sarah Scott tried to utter some object and name something, especially classified as noun and verb. As Broca aphasic person, Sarah had a problem with her language production. Thus, there are a lot of pauses in her utterances. When she had difficulty uttering something, Sarah had always doing humming and repeated the word twice or three times, such as"... also arm it's um the same as um. the same as kind of thing as um, you know." and "Oh.. um.. speech lang (language) um.. the.. speech.. umm". Moreover, this kind of characteristic also appears when Sarah Scott was communicating with other people. For example, it happened when she had a conversation with her mother in the video. When she got a question from her mother that she was suffering from what, she had difficulty finding the word "aphasia" to answer her question, then, she had to write down to make her easier to produce that word.

\section{b. Agrammatism}

Agrammatism also becomes a significant problem for Sarah Scott as a person with Broca's aphasia. It is characterized by a deficit in formulating and processing syntax. It also impaired auditory comprehension, such as the complex types of grammatical constructs. According to Hallowell (2017), agrammatism is a symptom caused by limited working memory and the deficit speed of processing capacity. The reduced power leads to difficulty receiving the information processed to be understood and produce the grammatical sentences. As a result, Sarah Scott tends to produce and 
understand only a few meaningful words. The function words produced by Broca's aphasic such as article and preposition tend to be omitted, and they may substitute the suffixes or affixes but more likely cannot produce the inflectional morphemes (Ardila, 2010, 2014).

In data 1, Sarah made a grammatical error in her utterance, "So, I stand there, " when she talked about how she had a stroke the first time. She should change the word "stand" into "stood" as the past form from that word. It happened because the auditory comprehension was impaired at Sarah Scott, who suffers from Broca's aphasia that causes the deficit to formulate and process syntax.

Meanwhile, in datum 7, Sarah said, "But it's I can't," which shows two subjects in her utterance where she should only put the subject " $I$ " as the appropriate subject for the context. Sarah should only use the subject $I$ because she tells herself whereas a person. The subject it is only used for inanimate objects.

Then, in datum 8, the grammatical error made by Sarah can be seen in the utterance "I'm fine sometimes that a long sentences". She shouldn't use the article " $a$ " in that utterance because the phrase "long sentences" is categorized as plural. It occurred when Joannie Scott asked Sarah how writing would make it easier for her to find the words she was talking about. Then Sarah replied, that she could write one word. Sometimes she could also write a long sentence. Sometimes she also can't read and write.

The agrammatism characteristics happened in the middle of her utterance.
When she produced the utterance, Sarah was always careful, and there was a hesitation when she was trying to say the word. As Broca aphasic person, Sarah had a problem producing the word. Besides, she also experiences the reduced working memory, so that she tends to cannot produce the sentence with the grammatical constructions.

\section{c. Literal (Phonemic) Paraphasia}

Literal (phonemic) paraphasia is the characteristic of Broca's aphasia which is also found on the Sarah Scott utterances in the SymphUK YouTube channel. Literal (phonemic) paraphasia occurs when a person with Broca's aphasia always substituted one more sound in the word. Furthermore, according to Ardila (2014), literal (phonemic) paraphasia is the symptom in which the patient was always doing phoneme substitution and phoneme omission. As a result, they had difficulty to produce specific phonemes such as fricative or affricative phonemes and produce complex syllables such as consonant-consonantvowel in the word tree.

The phoneme substitution that always occurs in people with Broca's aphasia is substituted the fricative phoneme with stop phoneme. For instance, phoneme /s/ in the word becomes are replaced with phoneme /t/. Meanwhile, the phoneme omission, which mostly occurs in people with Broca's aphasia, omits the complex syllable becomes the primary syllable, such as the word tree become tee. Not only that, the phoneme addition and phoneme displacement also might occur in a person with Broca's aphasia. For instance, the word pencil is adding 
phoneme /r/, so it become precil and the word pencil becomes pelcin which displacement the phoneme $/ \mathrm{n} /$ in the last word.

In datum 3, Sarah wanted to say the word "legs" but omitted the first phoneme of the word become "egs." It occurred in the context when she told her mother how she had a stroke. When she said that her leg suddenly fell while holding it, she misstated the word leg into the arm. After that, his mother confirmed that what she touched was a leg, not an arm. Instantly, Sarah Scott also confirmed what she was said, but with the wrong sound. She calls the word leg with egs.

Moreover, in datum 5, she said "Oh .. um .. speech lang. . ( language ) um .. the .. speech .. umm ..". In this utterance Sarah only said the word "lang." Still, instead, she wanted to say the word "language." It occurred in the context when Joannie Scott asked her about the activities she did after a stroke hit her. After that, Sarah Scott tried to mention language but then she replaced with speech. The word language has two syllables, therefore she chose the one syllable word like speech.

The last example was shown in datum 9; Sarah said: "Vell ( means well) it's hard .. and .. but, you should fight and speak a lot and .. um .. um .. ". In this context, she wanted to say the word "well," but she substituted the first phoneme become "vell.". This utterance occurred in the context when Joannie Scott asked Sarah Scott whether she can deliver a message to other people who also had suffered a stroke. Then Sarah Scott put it effortfully, and there are many pauses in her sentence. She said that it is hard, so we have to struggle and learn to speak a lot. In her utterance, those errors are classified as the problem of apraxia of speech in people with Broca's aphasia. Sarah had experienced a deficit of fluency, and the kinetic speech melodies are disintegration, the impairment of verbal-articulatory.

The literal (phonemic) paraphasias mostly happened in the middle of the utterance. It also occurred when Sarah produced the wrong word or the different word that she wants to say. She tends to omit and substitute the word. For example, when she tried to say the word legs become egs, the term language becomes lang, and the word well becomes vell. These errors were produced by Sarah Scott when she had a conversation with her mother.

\section{d. Disfluency}

Disfluency is a characteristic that mainly occurred in people with Broca's aphasia. According to Hallowel (2017), disfluent in people with Broca's aphasia only conveys fewer words. The content is less meaningful per unit of time than other types of aphasia and people without aphasia. People with Broca's aphasia also tend to be aware of these errors, especially in contrast to people with aphasia with more posterior (temporal lobe) lesions. As a result, some have extreme frustration when struggling to communicate.

In data 1, it occurred when Sarah talked about how the first time she had a stroke. She said, "Um .. um .. um ... [1.1] school [1.2], and English class, and I. um .. book and I read it aloud...". At the beginning of her utterance, there is humming three times before the word school. The humming is as a sign that 
she was thinking hard to continue what she wants to say. It is caused by the disruption of temporal lobe lesions in the brain to not produce a language and sentence wherein production becomes meaningless.

Meanwhile, in data 11, she said, "Mmm.. cat .. I hated it.. and .. also my .. um.. Dad is a.. um. . asthma.. and so.. um.. it's a life long so summer sad but..". This utterance occurred in the context when Sarah Scott explained that she got a dog, and she was talking about why she prefers to have a dog than a cat. When she tried to explain that, Sarah had difficulty conveying the word that she wanted to say, so there are many pauses and humming in her utterance. There are humming at the beginning of the sentence and three times in the middle of the sentence; before she says the word Dad, Asthma, and it's life. Disfluent characteristics appeared when Sarah tried to explain something. As Broca's aphasic person, she had challenges producing the word, so that there are many pauses and humming in her utterances. Humming is often appeared at the beginning of the sentence and also in the middle of the sentence.

\section{e. Repetition}

Repetition is one of the characteristics which occur in people with Broca's aphasia. Ardila (2014) stated that repetition symptoms caused by different mechanisms are limitation of auditory verbal short-term memory, difficulties at the level of phonological production, impairments in phoneme recognition, and semantic and syntactic comprehension. Therefore, according to the specific task, the error of Broca aphasic person can be seen in the difficulties at phonological production and defects in grammar comprehension.

From the data analysis, which can be seen in the research finding, the researchers found several utterances produced by Sarah Scott, classified as repetition in the SymphUK YouTube channel. It can be seen in datum 6; She said, "And.. and.. and.. connect.". This utterance occurred in the context when Joannie Scott asked her daughter, Sarah about what activities she did after a stroke. Sarah tried to explain the activities she did after having a stroke. Those are speech therapy, riding horses, and the last one was connected. The last activity is part of speech therapy in which, as a person who suffering from problems in producing language, Sarah often has to learn to formulate words. However, when answering the last activity, Sarah Scott repeated the word and three times

In another example of repetition, in data 10, Sarah said: "Um.. well I think .. I think that .. I think.. it.. it's.. I think later on still think it's too much and.. I think .. I still.. think writing and speaking, I think .. I'm always gonna think it's hard so I just think and just to have work but what I don't know because I'm it's difficult.". Sarah repeated the phrase "I think" three times and the phrase "it's" twice at the exact times. This utterance occurred when Joannie Scott asked Sarah Scott about the university off the following year and how about her future. Then, Sarah tried to answer it with effort and repeated the exact words many times, so her utterance was challenging to understand. Finally, she said that it was tricky, but she had to work hard to 
recover her language skills, such as speaking and writing.

The repetition's symptom appeared when Sarah tried to convey something. As Broca aphasic person, she had difficulty with producing the word. So that, there are many pauses in her utterances, and she repeated the same word many times to continue the next term. For example, as explained in datum 6, Sarah repeated the word and continued the word connect. Therefore, it can be inferred that repetition is the symptom of sensory perception, motor speech capacity, inner speech, the understanding of the material that has been repeated, attitude and educational level of the subject, and the context in which the repetition occurs.

\section{f. Telegraphic Speech}

Telegraphic speech was also found in the Sarah Scott utterances as Broca aphasic person in the SymphUK channel. Telegraphic speech occurs in a person with Broca's aphasia, which cannot produce complex sentences. They often have short sentences such as a single word (Ardila, 2014). In addition, a person with Broca's aphasia tends to omit the function word such as prepositions, pronouns, determiners, conjunctions, and auxiliary verbs, which refers to the closed class words that relatively be a small set of the language to compare with open class words. The content word such as nouns, verbs, adjectives, and adverbs also tends to omit on the person with Broca's aphasia, which refers to open class words used and combined with other class words arrange the sentences (Hallowell, 2017).

The researchers found telegraphic speech in the Sarah Scott utterances in SymphUK YouTube channel from the research finding. It can be seen in the data 1. At the beginning of the word, Sarah said, "...school, and English class, and I.. um.. book...". From this sentence, Sarah only said the short sentence as a single word categorized as a noun. Her sentences were not completed with any function words that must be arranged to make a complex sentence. The telegraphic speech appeared when she tried to explain something. She also used the gesture to make her easier to speak. For instance, when she said the word books, she used her hands and acted like holding a book. The analysis summary based on the theory by Hallowel (2017) is presented in figure 1

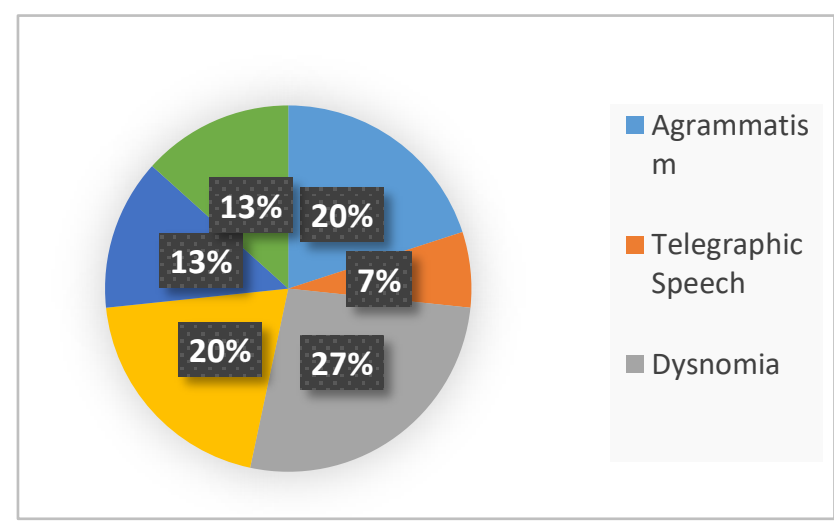

Figure 1. The characteristics of Broca's aphasia in Sarah's utterances 


\section{CONCLUSION}

Based on the analysis of the study, the researcher concluded that Sarah Scott had several problems, which leads to the characteristics of Broca's aphasia and the levels of language impairments that affect her speaking ability. The significant problem had by Sarah as a person with aphasia is remembering the name of something or object. She also had difficulty finding the right word, so that she had to gesture her hand to help her find the word that she wanted to say.

Furthermore, Broca's aphasia also made her speaking ability was disturbed, mainly to produce the sentence. She had the problem of producing the sentence with the correct grammatical. Therefore, it made difficult to understand and also there are many pauses and repetition in her utterance. The phonological system of Sarah Scott was also disturbed, which made her utterance tend to omit and substituted the phoneme of the word. That difficulty is the condition of Sarah Scott as people with Broca's aphasia in the SymphUK YouTube channel.

Based on the utterances produced by Sarah Scott, the researcher found twenty-six problems of Sarah Scott, which related to the characteristics of Broca's aphasia. Through using the Hallowel (2017) and Ardila (2014) theory, the researcher concluded that the most dominant characteristic found in Sarah Scott is dysnomia. The following characteristics are literal (phonemic) paraphasia and agrammatism. Then the other characteristics are disfluent, repetition, and telegraphic speech.

The following finding is about the levels of language impairment that affect the speaking ability of Sarah Scott based on the theory proposed by Ardila (2013, 2014). According to Ardila and Benson (1996), Broca-type aphasia had two major problems: the motor level related to the phonetic-level error and reducing the grammar, referred to as agrammatism. Ardila (2014) also classified the levels of language-impaired in Broca's aphasia are morphemic, morphosyntactic, and phonetic. The language levels that the most damaged in Sarah Scott as people with Broca's aphasia are phonetic. She often omitted the last phoneme and substituted the phoneme at the beginning of the word. Other levels impaired in Sarah Scott are morphosyntactic and morphemic.

In this study, the researchers found that Sarah Scott, as Broca aphasic person, had a problem that led to Broca's aphasia and the levels of language impairments that affect her speaking ability. Sarah was very effortful to communicate with others, and sometimes she looks surrender with her condition. Therefore, the researcher applies the suggestion for people facing people with aphasia to care more about them.

As explained in the previous section, a person with aphasia have several difficulties in producing language. Thus, people who interact with them must be patient to comprehend what they are saying about. It is caused by their language deficit, so that they cannot produce the word correctly. However, this study can be used as a reference for a better understanding of language impairment, especially understanding the characteristics of Broca's aphasia. 


\section{REFERENCES}

Ardila, A. (2010). A proposed reinterpretation and reclassification of aphasia syndromes. Aphasiology, 366.

Ardila, A. (2013). A New Classification of Aphasias. Departments of Communication Science Disorder.

Ardila, A. (2014). Aphasia Handbook. Florida: Florida International University.

Ardila, A., \& Benson. (1996). Aphasia: A clinical perspective. New York: Oxford University Press.

Azad, O. (2020). Lexical Ambiguity Processing in Persian-speaking Patients with Broca and Wernicke Aphasia. Modern Rehabilitation, 39.

Beverley, H. (1998). An Introduction to Qualitative Research. Nottingham: The Trent Focus Group.

Bodgan, R. C., \& Biklen, S. K. (1982). Qualitative Research For Education (An Introduction to Theory and Methods). Syracuse: Nancy Forsyth.

Code, C. (2019). The Cambridge Handbook of Psychology, Health and Medicine (pp.428). Cambridge: Cambridge University Press.

Ellis, C., Phillips, R., Hill, T., \& Briley, P. M. (2019, August). Social network structure in young stroke survivors with aphasia: A case series report. In Seminars in speech and language (Vol. 40, No. 05, pp. 359-369). Thieme Medical Publishers.

Hallowell, B. (2017). Aphasia and Other Acquired Neurogenic Language Disorder : a guide for clinical excellence. San Diego: Plural Publishing.

Heal, B. (2019). Word Error and Word Frequency Correlation in Broca's aphasia. Speech Pathology and Audiology Commons .

Indah, R. N. (2011). Gangguan Berbahasa. Malang: UIN Press.

Indah, R. N., \& Abdurrahman. (2008). Psikolinguistik: Konsep \& Isu Umum. Malang: UIN Press.

Jordan, L., \& Keiser, W. (1996). Aphasia- A Social Approach. Canada: Chapman \& Hall.

Nichcy, N. D. (2011). Speech and Language impairment. Disability Fact Sheet, 3.

Project, I. C. (2021, January 21). Retrieved from International Communication Project: https://internationalcommunication project.com/profile/an-18-year-oldwith-aphasia-sarahs-story/

Rahmi, E., \& Arianto, T. (2019). Schizophrenia Symptoms Acute in Teddy Alias Andrew in The "Shutter Island" Novel by Dennis Lehane. Jurnal Basis, 6(2), 225236.

http://ejournal.upbatam.ac.id/index. $\mathrm{php} / \mathrm{basis} /$ article/view/1422

Reily, J. (2014). Language Disorder. Encyclopedia of Theory in Psychology, 3.

Septianto, R. D. (2020). A Case of Language Disorder on Aphasia and Its Phonological Error Found Within Edwyn Collins Utterances as A Main Character in The Possibilities Are Endless Movie. Surakarta: Unpublished Undergraduate Thesis.

Souchon, N. M., Krüger, E., Eccles, R., \& Pillay, B. S. (2020). Perspectives 
of working-age adults with aphasia regarding social participation. African Journal of Disability, 9.

Syarifah, W. H. (2020). Broca's aphasia Word Production on My Beautiful Broken Brain Movie. Malang: Unpublished Undergraduate Thesis. Withaker, H. A. (2007). Language Disorder: Aphasia. Encyclopedia of Language and Linguistics, 10.

Yulia, H., Syarif, H., \& Marlina, L. (2018). The Syntactical Analysis of The Influence of Speech Therapy to Post Stroke Patients With Broca's aphasia Speech Ability. E-Journal of English Language \& Literature, 422-431. 